Research Article

\title{
Study on Energy Consumption Characteristics of Different Tools under Impact Load
}

\author{
Fujun Zhao $\mathbb{D}^{1,2}$ Haifan Wang $\mathbb{D}^{1},{ }^{1}$ Zhouyuan Ye, ${ }^{1,2}$ Yonghong Liu, ${ }^{1}$ and $\mathrm{Yu} \mathrm{Li} \mathbb{D}^{1}$ \\ ${ }^{1}$ College of Resources, Environment and Safety Engineering, Hunan University of Science and Technology, \\ Xiangtan, Hunan 411201, China \\ ${ }^{2}$ Hunan Provincial Key Laboratory of Coal Mine Safety Mining Technology, Hunan University of Science and Technology, \\ Xiangtan, Hunan 411201, China \\ Correspondence should be addressed to Fujun Zhao; zfjxxn@263.net
}

Received 3 March 2019; Revised 23 May 2019; Accepted 3 July 2019; Published 17 July 2019

Academic Editor: Marco Corradi

Copyright (c) 2019 Fujun Zhao et al. This is an open access article distributed under the Creative Commons Attribution License, which permits unrestricted use, distribution, and reproduction in any medium, provided the original work is properly cited.

\begin{abstract}
Three different tools for rock breaking were designed and fabricated. Impact crushing tests were conducted on granite samples with an identical impact velocity by using the variable section Split Hopkinson pressure bar (SHPB) test device. In the test, the incident energy, absorbed energy, and cumulative energy values of acoustic emission during the process of rock breaking were collected, and energy utilization efficiency was used as a measure of the energy consumption characteristics for three different tools breaking rock. Experimental results showed that the cruciform tool has the best performance with respect to the energy utilization efficiency, followed by the one-shaped tool and the spherical tool. The cumulative energy values of the acoustic emission of different tools follow the same regularity.
\end{abstract}

\section{Introduction}

During the process of rock deformation and destruction, material and energy are interactive with the environments. The macroscopic fracture of the material is the final result of the continuous development, expansion, aggregation, and penetration of the microcrack. The process from microscopic damage to macroscopic fracture is a response of energy dissipation [1]. There are many researches on the mechanical properties of rock under impact loading [2,3]. Li et al. used a conical pick to perform true triaxial hard rock fracture experiments on cube rock specimens of different sizes [4-6]. An experimental study was conducted [7] to analyze the dynamic compressive strength, failure mode, and crack propagation characteristics of preformed hole samples under impact load. The fracture energy consumption characteristics of sandstone specimens under impact load were studied systematically in paper [8] by using SHPB, which shows that the ratio of absorbed energy to incident energy of sandstone specimens is relatively constant and increases linearly with incident energy. It is found that the energy consumption under impact load is related to rock fragmentation, cutting speed, rock hardness, etc. Energy utilization is reflected by the energy consumption characteristics under these factors [9-12]; Xia et al. [13] pointed it out that the porosity under the impact load plays an important role in rock energy dissipation.

Li et al. [14] found that in the process of rock fragmentation, the energy utilization efficiency has a significant downward trend with the increase of incident energy. Through numerical simulations and experimental studies, Zhao et al. [15], Xie et al. [16] found that simply improving the impact load will not greatly improve the rock breaking effect. Instead, an optimal rock breaking impact energy exists.

It can be found in [17] that the acoustic emission energy released by the static intrusion of the tool into the unit volume of rock is related to the loading rate, rock compressive strength, rock elastic modulus, tool shape, and the friction coefficient of the tool and the rock.

The above studies are based on the test results and theoretical analysis under a single flat end indenter; however, 
only limited investigations have been done on the rock breaking effect and energy dissipation law of different tools under high strain rate. Therefore, this paper takes the brittle rock granite as the research object to test the performance of different tools. Based on the SHPB test platform, a set of test devices has been developed to conduct the impact rock breaking test of different tools under high strain rate. Our study will be of great significance for deepening rock fracture mechanism and improving rock breaking tools and rock breaking technology.

\section{Test Overview}

2.1. Sample Preparation. Brittle rock granite is selected as the rock sample in this test. According to the design requirements of the test plan, the sample used in the test is a cube of $100 \mathrm{~mm} \times 100 \mathrm{~mm} \times 100 \mathrm{~mm}$, and the elastic bar is a circular cylindrical bar with diameter of $50 \mathrm{~mm}$ in cross section. The selection of the size of the test piece was made after reference to many scholars' relevant research studies [4-6, 18-24]. The contact between the tool and the surface of the rock sample is line contact (one-shaped type, cruciform type) and point contact (spherical type), which is a noncoupling contact, and the other end of the sample is in surface contact with the output bar. To better avoid the boundary effect, the cross-sectional area of the test piece is exactly larger than the cross-sectional area of the elastic member. According to the performance requirements of rock mechanics test, the sample is polished with a grinder. The flatness of both ends is less than $0.05 \mathrm{~mm}$, and the parallelism is less than $0.02 \mathrm{~mm}$. The static mechanical properties of granite specimens are tested by RMT-150C rock mechanics tester. The physical and mechanical parameters are given as follows: density $\rho=2.6 \times 10^{3} \mathrm{~kg} / \mathrm{m}^{3}$, elastic modulus $E=21.35 \mathrm{GPa}$, compressive strength $\delta_{\mathrm{c}}=106.46 \mathrm{MPa}$, Poisson's ratio $\nu=0.09$, and tensile strength $\delta_{\mathrm{t}}=7.65 \mathrm{MPa}$. The test is divided into three groups, with three samples in each group. The sample numbers of the one-shaped tool rock breaking are marked as A1, A2, and A3; the sample numbers of the spherical tool rock breaking are marked as B1, B2, and B3, and the sample numbers of the cruciform tool rock breaking are marked as $\mathrm{C} 1, \mathrm{C} 2$, and $\mathrm{C} 3$, respectively.

2.2. Test Principle. To achieve different rock breaking tests at high strain rates, a set of test devices is independently developed in this paper using the SHPB test platform. The test device is shown in Figure 1, which mainly consists of a SHPB device, a sample support device, and a tool fixing device. The material used in this device is the same as the SHPB device, which is $40 \mathrm{Cr}$ alloy steel with an elastic limit up to $800 \mathrm{MPa}$. The sleeve of the incident bar, the sleeve reinforcement screw, and the sample pad are specially processed. Figure 2 shows the three tools used in the experiment. The length of the tool for the one-shaped tool is $4 \mathrm{~cm}$, the cruciform tool has a cross length of $4 \mathrm{~cm}$, and the diameter of the spherical tool is also $4 \mathrm{~cm}$.

According to the homogenization condition of the SHPB device, the stress wave is repeatedly reflected by the rock sample, resulting in the balance of the stress and strain at both ends, and the stress $\sigma_{\mathrm{t}}$, strain $\varepsilon_{\mathrm{t}}$, and strain rate $\dot{\varepsilon}_{\mathrm{t}}$ of the rock sample can be obtained, which can be calculated by [19]

$$
\begin{aligned}
& \sigma(t)=\frac{A_{\mathrm{e}} E_{\mathrm{e}}}{2 A_{\mathrm{s}}}\left[\varepsilon_{\mathrm{I}}(t)+\varepsilon_{\mathrm{R}}(t)+\varepsilon_{\mathrm{T}}(t)\right], \\
& \mathcal{E}(t)=\frac{C_{\mathrm{e}}}{L_{\mathrm{s}}} \int_{0}^{t}\left[\varepsilon_{\mathrm{I}}(t)-\varepsilon_{\mathrm{R}}(t)-\varepsilon_{\mathrm{T}}(t)\right] d t, \\
& \dot{\varepsilon}(t)=\frac{C_{\mathrm{e}}}{L_{\mathrm{s}}}\left[\varepsilon_{\mathrm{I}}(t)-\varepsilon_{\mathrm{R}}(t)-\varepsilon_{\mathrm{T}}(t)\right],
\end{aligned}
$$

where $A_{\mathrm{s}}$ and $A_{\mathrm{e}}$ are the area of the sample and the pressure bar, respectively; $E_{\mathrm{e}}$ is the elastic modulus of the pressure bar; $\varepsilon_{\mathrm{I}}, \varepsilon_{\mathrm{R}}$, and $\varepsilon_{\mathrm{T}}$ are incident, reflected, and transmitted stress waves at time ( $\mathrm{t}$ is time); $C_{\mathrm{e}}$ is the wave speed of the pressure bar; and $L_{\mathrm{s}}$ is the length of the sample.

2.3. Energy Calculation. During the impact compression, in order to ignore the energy consumed by the friction which is produced by the contact between the incident bar and the sample, as well as the sample and the transmission bar, lubricant is applied to both ends of the sample. The rock sample absorbs energy during dynamic impact compression and destruction, which can be calculated by the following formula [24]:

$$
E_{\mathrm{S}}=E_{\mathrm{I}}-E_{\mathrm{R}}-E_{\mathrm{T}}
$$

where $E_{\mathrm{S}}$ is the absorption energy of the test piece, $E_{\mathrm{I}}$ is the incident energy, $E_{\mathrm{R}}$ is the reflection energy, and $E_{\mathrm{T}}$ is the transmission energy. $E_{\mathrm{I}}, E_{\mathrm{R}}$ and $E_{\mathrm{T}}$ can be given as follows [24]:

$$
\begin{gathered}
E_{\mathrm{I}}=\frac{A_{\mathrm{e}}}{\rho_{\mathrm{e}} C_{\mathrm{e}}} \int_{0}^{\tau} \sigma_{\mathrm{I}}^{2}(t) d t, \\
E_{\mathrm{R}}=\frac{A_{\mathrm{e}}}{\rho_{\mathrm{e}} C_{\mathrm{e}}} \int_{0}^{\tau} \sigma_{\mathrm{R}}^{2}(t) d t, \\
E_{\mathrm{T}}=\frac{A_{\mathrm{e}}}{\rho_{\mathrm{e}} C_{\mathrm{e}}} \int_{0}^{\tau} \sigma_{\mathrm{T}}^{2}(t) d t .
\end{gathered}
$$

The energy consumption of the test piece mainly includes crushing energy, ejection kinetic energy, and other energy consumption. The energy consumption of the fracture is the energy consumed by the expansion of the original crack in the test piece, the new crack, and the microcrack of the fragment. The kinetic energy of the projectile is the kinetic energy of the broken rock produced by the fracture of the specimen. Other energy consumption includes acoustic energy, thermal energy, radiant energy, and the energy that is dissipated from the rock sample around. According to the research by Pingqi [8], ejection kinetic energy and other energy consumption account only a small proportion, which are normally hard to directly measure. Therefore, the crushing energy can be used to replace the consumption energy with negligible error. Thus, the energy utilization efficiency $\eta$ can be expressed by the following formula [10]: 


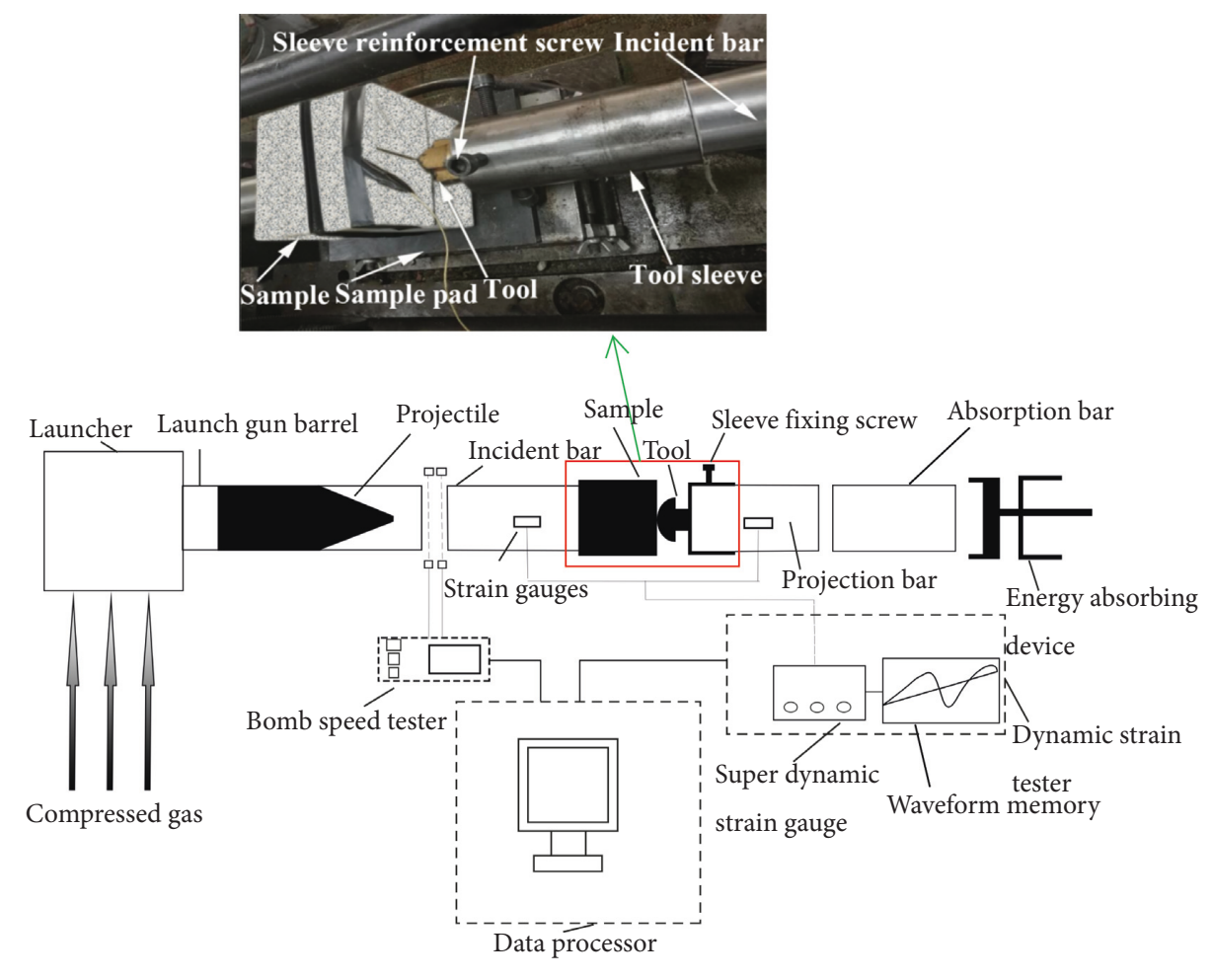

Figure 1: Test device.

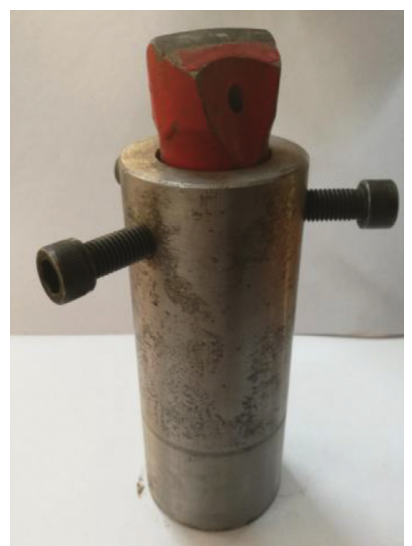

(a)

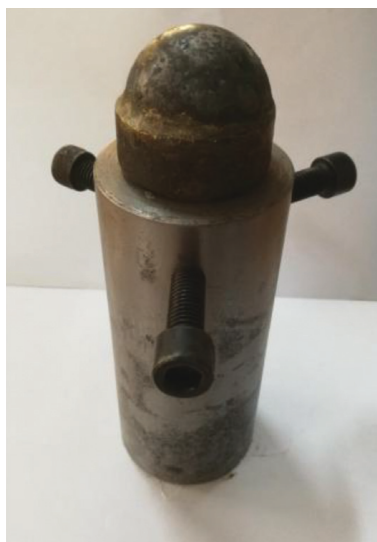

(b)

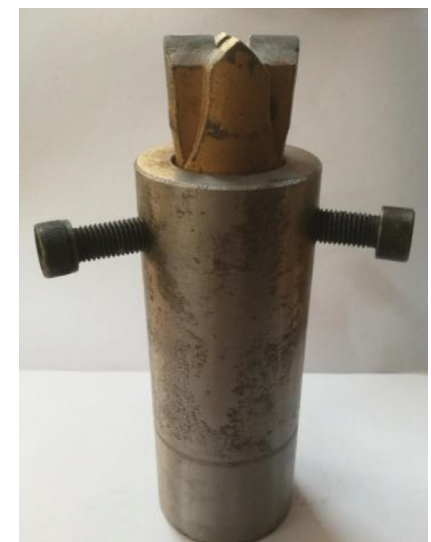

(c)

Figure 2: Tools with different end faces. (a) One-shaped tool. (b) Spherical tool. (c) Cruciform tool.

$$
\eta=\frac{\sum E_{\mathrm{S}}}{\sum E_{\mathrm{I}}} \times 100 \%
$$

where $\eta$ is energy utilization efficiency, $\sum E_{\mathrm{S}}$ is total absorbed energy, and $\sum E_{\mathrm{I}}$ is total incident energy.

2.4. Test Procedure. According to the uniaxial compression test, the impact pressure of $0.6 \sim 0.8 \mathrm{MPa}$ is selected for the test, the loading waveform is set to a sine wave, the strain gauge is attached to the corresponding position on the incident bar and the transmission bar on the SHHP device, and the incident bar end and the end face of the transmission bar are evenly coated with butter to reduce friction; the incident bar, the transmission bar, and the sample are adjusted to keep them parallel, and the end face of the sample is well contacted with the two end faces. Clicking on the acoustic emission signal acquisition system, the acquisition command activates the punch launching mechanism and the impact air pressure reaches a predetermined value. Then the drive bullet, the acoustic emission, and the strain gauge data acquisition system receive the acoustic emission signal and the waveform signal, and the test data is saved and processed. During the process of impacting the rock specimen, the AEwin-USB type acoustic emission monitoring system is used to collect and record the acoustic emission amplitude 
and energy in the experiment. The sensor attached to the surface of the rock specimen will make the force that the impact brings to the test piece be converted into a signal that can be collected by the system. The system allows the acquisition of global waveforms, which is crucial for the data acquisition and analysis of the experimental results.

\section{Analysis of Experimental Results}

The impact waveform of different tool crushed granite samples under the impact load is shown in Figure 3. In this paper, the cumulative energy of acoustic emission in the acoustic emission characteristic parameters is selected as the rock failure characteristic parameter. Figure 4 shows the cumulative energy of the acoustic emission of different tools under the impact load over time. It should be noted that although the time corresponding to the sampling points of the SHPB device and the acoustic emission acquisition system cannot be well matched, the total duration of the stress action time and the acoustic emission acquisition time is always the same.

From the impact test stress waveform and energy dissipation calculation equations (2) and (3), the incident energy, reflected energy, transmitted energy, and absorbed energy in the process of crushing granite with the oneshaped tool, spherical tool, and cruciform tool can be calculated, respectively. The curves of incident energy and absorbed energy of different tools under different impact loads are shown in Figure 5.

From Figure 5, it is evident that the incident energy and the absorbed energy of different tools show the same change trend under the impact load. In the initial stage of rock breaking, the incident energy and the absorbed energy increase uniformly with time. After reaching a certain moment, the energy remains constant, that is, the energy stops growing. However, there are also differences among different tools. It can be seen from Figure 3 that the incident energy and the absorbed energy of the cruciform tool increase faster than other tools; thus, the acoustic emission signal of the cruciform tool is firstly generated during the rock breaking process, as shown in Figure 4 . When the acoustic emission energy reaches the maximum value, there is no crack development and expansion inside the rock. It means that the granite specimen is completely destroyed. Therefore, it can be concluded that the incident energy during the rock broken process of the cruciform tool is the largest, followed by the one-shaped tool, and the spherical tool is the smallest. The cumulative energy of the acoustic emission accompanying the rock crushing process follows the same order, as shown in Figure 4. Since the cruciform and one-shaped tools are in line contact with the specimen (where the cruciform tool is equivalent to two one-shaped tools), and the spherical tool is point contact, within a given impact pressure range, the cruciform tool absorbs more energy during rock breaking. Most of the absorbed energy of the sample is dissipated in the damage evolution process of the microcrack of the sample, eventually forming the macroscopic damage. The level of acoustic emission activity is closely related to crack propagation with positive correlation.

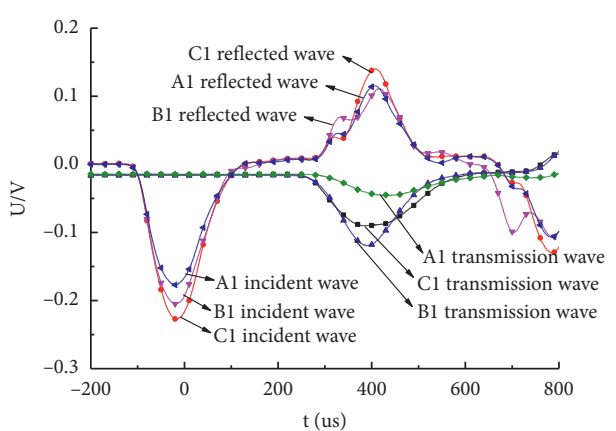

FIgURE 3: The impact waveform of granite sample under different tools.

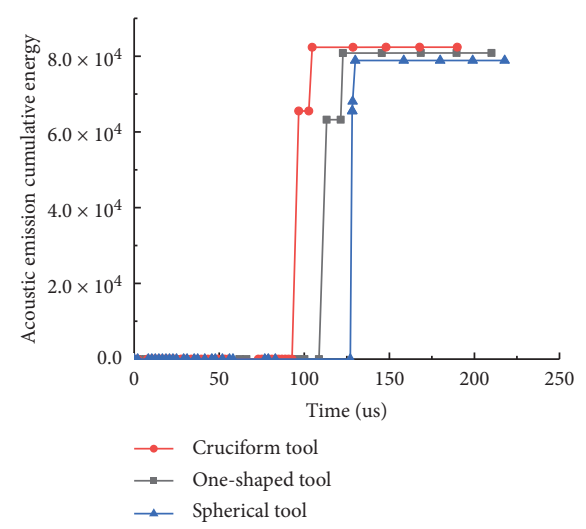

FIgURE 4: The cumulative energy characteristic curve of acoustic emission of different tools.

According to the test results, the statistical table of rock breaking energy characteristics parameters of different tools under impact load is given in Table 1 . It can be evidently seen that the cruciform tool under impact load has the highest energy utilization efficiency, followed by the one-shaped tool and the spherical tool. Figure 6(a) shows the rock breaking characteristics of different tools under the impact load. The cruciform tool breaks the rock into a cruciform damage, while the one-shaped and spherical tools break the rock in a line-shaped damage. Figure 6(b) shows the degree of fragmentation of the sample under different tools. When the cruciform tool breaks the rock, the small particle size block has the largest proportion and the rock breaking time is the shortest, followed by the one-shaped tool and the spherical tool. Therefore, we can draw such a conclusion that the cruciform tool has the best rock breaking effect, followed by the one-shaped tool and the spherical tool.

In this experiment, the rock is subjected to impact crushing under three different types of rock breaking tools, and the energy dissipation analysis is carried out. In the relevant literature referenced at present, there is no use of different shape tools as experimental variables. The experiment of analyzing the energy consumption of rock crushing, this experiment is also a new small angle to the general direction of rock dynamic mechanics. It is a supplement to the research angle of impact tool shape in rock dynamic mechanics, and the study of consumption is 


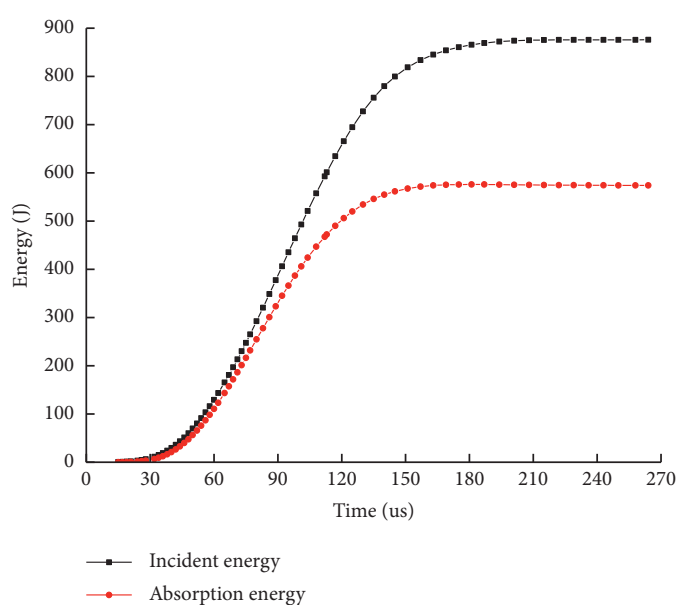

(a)

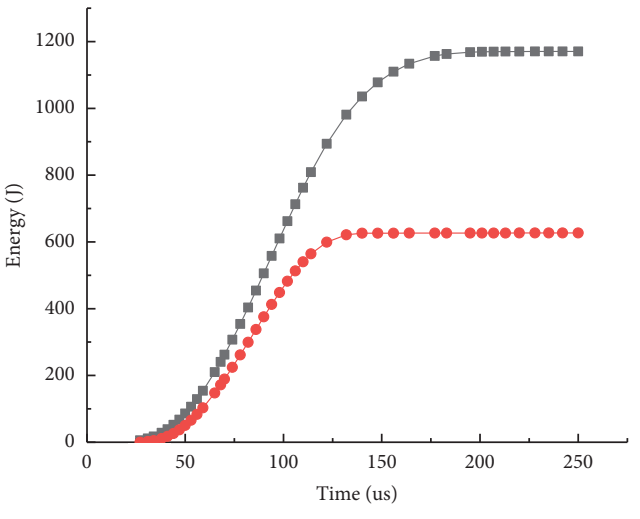

$\rightarrow$ Incident energy

$\rightarrow$ Absorption energy

(b)

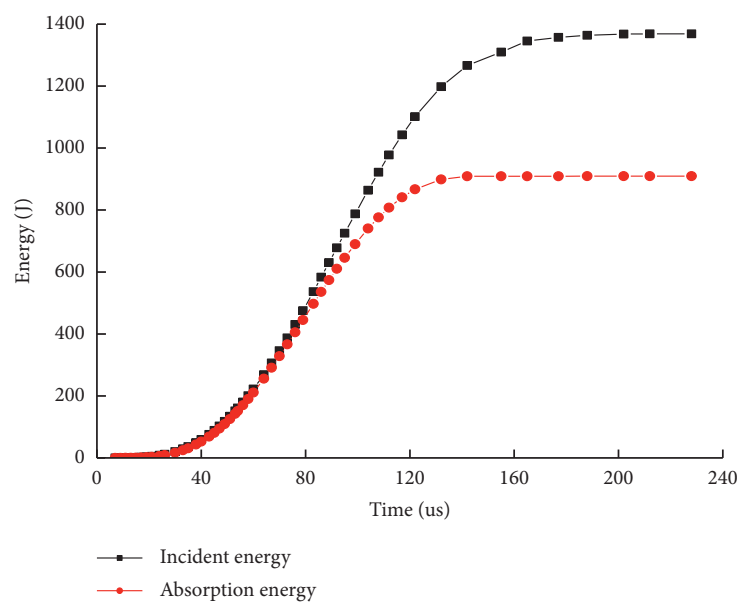

(c)

FiguRE 5: Rock breaking energy characteristic curves of different tools: (a) one-shaped tool, (b) spherical tool, and (c) cruciform tool.

TABLE 1: Characteristics of rock breaking energy characteristics of different tools under impact load.

\begin{tabular}{lcccc}
\hline Tool & Total absorbed energy $(J)$ & Total incident energy (J) & Energy utilization efficiency $\eta(\%)$ & $\begin{array}{l}\text { Acoustic emission } \\
\text { cumulative energy }\end{array}$ \\
\hline One-shaped & 575 & 975 & 58.97 & 80866 \\
Spherical & 526 & 1140 & 46.14 & 78866 \\
Cruciform & 944 & 1368 & 69.01 & 82374 \\
\hline
\end{tabular}

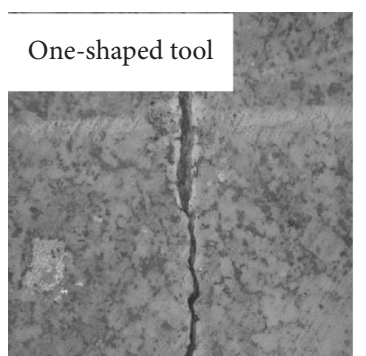

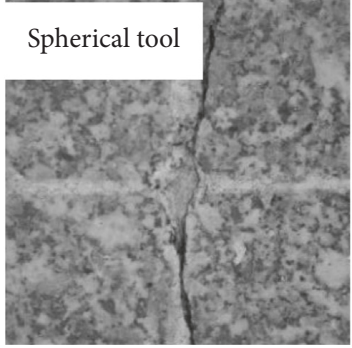

(a)

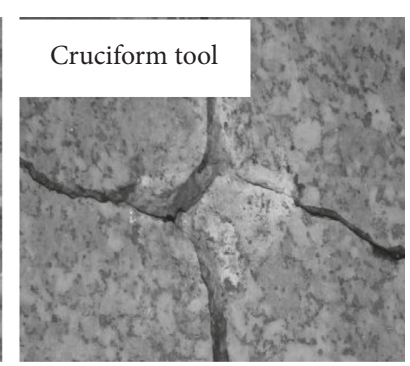

Figure 6: Continued. 

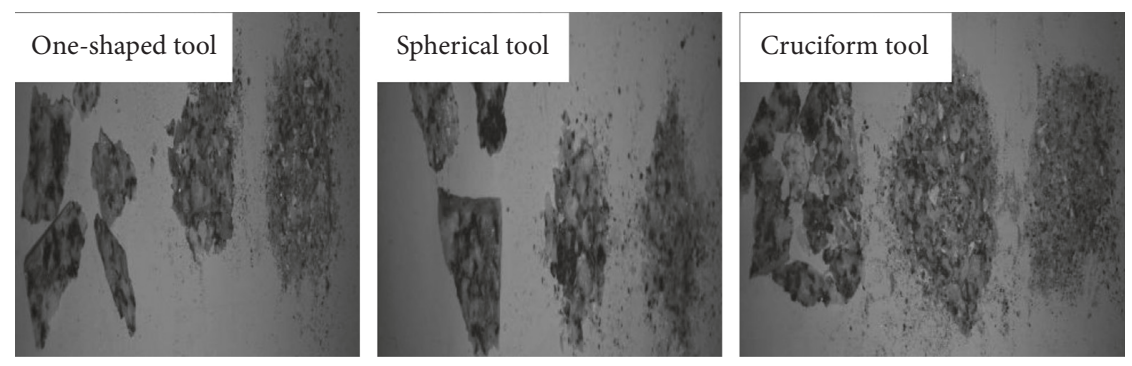

(b)

FIGURE 6: Rock breaking characteristics of different tools under impact load. (a) Sample failure form under different tools. (b) Degree of fragmentation under different tools.

theoretical. In this experiment, the damage form obtained from the experimental results shows that under different tool impacts, the specimen is more completely damaged by the cruciform tool, compared with the one-shaped and spherical tools; the sample is broken into two halves and the cruciform tool breaks the specimen into four pieces; the effect of breaking the rock is obviously better; and the structure of the cruciform tool is more complicated and it can generate more friction with the rock when impacting the rock, which is one of the reasons for the high energy utilization of the cruciform tool. So for the $100 \mathrm{~mm} \times 100 \mathrm{~mm} \times 100 \mathrm{~mm}$ cubic granite samples selected by the experiment, the cruciform tool has the best effect and the highest energy utilization rate through the experimental impact and data acquisition results.

\section{Conclusion}

Through the theoretical analysis and experimental results, the following conclusions can be drawn:

(1) Under the impact load, the absorbed energy increases with the incident energy during the process of rock fragmentation.

(2) The incident energy and absorbed energy of the cruciform tool are the largest in the process of rock breaking, followed by that of the one-shaped tool, and the spherical tool has the smallest energy. Furthermore, the cumulative energy of the acoustic emission with the rock crushing process shows the same order.

(3) Under the impact load, the cruciform tool has the largest proportion of broken rock mass, the shortest rock breaking time, and the highest energy utilization efficiency, followed by the one-shaped and spherical tools. Therefore, the cruciform tool has the best rock breaking effect among them.

\section{Data Availability}

The data used to support the findings of this study are included within the article.

\section{Conflicts of Interest}

The authors declare that they have no conflicts of interest.

\section{Acknowledgments}

This study was funded by the National Natural Science Foundation of China (nos. 51474103 and 51647216); Hunan Provincial Natural Science Foundation Project (2017JJ2082).

\section{References}

[1] H. Xie, R. Peng, and Y. Yang, "Analysis of energy dissipation during rock deformation and failure process," Chinese Journal of Rock Mechanics and Engineering, vol. 21, pp. 3565-3570, 2004.

[2] Q. Wu, L. Weng, Y. Zhao, B. Guo, and T. Luo, "On the tensile mechanical characteristics of fine-grained granite after heating/cooling treatments with different cooling rates," Engineering Geology, vol. 253, pp. 94-110, 2019.

[3] Q. H. Wu, L. Chen, B. T. Shen et al., "Experimental investigation on rockbolt performance under the tension load," Rock Mechanics and Rock Engineering, pp. 1-14, 2019.

[4] S. Wang, X. Li, K. Du, and S. Wang, "Experimental investigation of hard rock fragmentation using a conical pick on true triaxial test apparatus," Tunnelling and Underground Space Technology, vol. 79, pp. 210-223, 2018.

[5] X. Li, S. Wang, and S. Wang, "Experimental investigation of the influence of confining stress on hard rock fragmentation using a conical pick," Rock Mechanics and Rock Engineering, vol. 51, no. 1, pp. 255-277, 2018.

[6] X. Li, K. Du, and D. Li, "True triaxial strength and failure modes of cubic rock specimens with unloading the minor principal stress," Rock Mechanics and Rock Engineering, vol. 48, no. 6, pp. 2185-2196, 2015.

[7] D. Li, T. Cheng, W. Zhou et al., "Experimental study on dynamic mechanical failure characteristics of marble containing pores under impact load," Chinese Journal of Rock Mechanics and Engineering, vol. 34, no. 2, pp. 249-260, 2015.

[8] P. Qi, X. Luo, Q. Ma et al., "Energy consumption characteristics of sandstone specimen under impact load," Chinese Journal of Rock Mechanics and Engineering, vol. 34, no. 2, pp. 4197-4203, 2015.

[9] X. Liu, R. Zhang, and J. Liu, "Experimental study on the relationship between coal and rock fragmentation and energy consumption under impact load," China Coal, vol. 40, no. 6, pp. 45-49, 2014.

[10] J. Su, Analysis of Energy Dissipation Characteristics of Rock Cutting and Crushing under Impact Load, Yanshan University, Qinhuangdao, China, 2014.

[11] H. Xie, Y. Yang, and L. Li, "Rock strength and global failure criterion based on energy dissipation and release principle," 
Chinese Journal of Rock Mechanics and Engineering, vol. 24, no. 17, pp. 3003-3010, 2005.

[12] D. Gan, Z. Liu, Z. Li et al., "Energy consumption characteristics of magnetite ore crushing under impact load," Chinese Journal of Rock Mechanics and Engineering, vol. 37, no. 1, pp. 3500-3506, 2018.

[13] C. Xia, H. Xie, Y. Yang et al., "Experimental study on energy dissipation of pore rocks under impact load," Engineering Mechanics, vol. 9, pp. 1-5, 2006.

[14] S. Li, W. Zhu, L. Niu et al., "Influence of loading rate on sandstone fracture and energy consumption characteristics," Journal of Northeastern University (Natural Science), vol. 38, no. 10, pp. 1459-1463, 2017.

[15] F. Zhao, L. Yu, Z. Ye et al., "Research on acoustic emission and electromagnetic emission characteristics of rock fragmentation at different loading rates," Shock and Vibration, vol. 2018, Article ID 4680879, 8 pages, 2018.

[16] S. Xie, Y. Wang, and F. Zhao, "Numerical simulation and experimental study of rock failure under impact load," China Tungsten Industry, vol. 5, pp. 5-9, 2007.

[17] L. Yu, F. Zhao, W. Chen, Y. Fan, and S. Zhang, "Theoretical analysis and numerical simulation of acoustic emission energy of cutting rock," Mining Research and Development, vol. 37, no. 10, pp. 62-66, 2017.

[18] Y. Su, J. Li, C. Wu, P. Wu, M. Tao, and X. Li, "Mesoscale study of steel fibre-reinforced ultra-high performance concrete under static and dynamic loads," Materials \& Design, vol. 116, pp. 340-351, 2017.

[19] W. Chen, L. Luo, Z. Guo, and H. Zou, "Strain rate effects on dynamic strength of high temperature-damaged RPC-FST," Journal of Constructional Steel Research, vol. 147, pp. 324-339, 2018.

[20] G. M. Ren, H. Wu, Q. Fang, and J. Z. Liu, "Effects of steel fiber content and type on dynamic compressive mechanical properties of UHPCC," Construction and Building Materials, vol. 164, pp. 29-43, 2018.

[21] W. Zhang, Y. Zhang, and G. Zhang, "Static, dynamic mechanical properties and microstructure characteristics of ultra-high performance cementitious composites," Science and Engineering of Composite Materials, vol. 19, no. 3, 2012.

[22] C. Jiao and W. Sun, "Impact resistance of reactive powder concrete," Journal of Wuhan University of Technology-Mater. Sci. Ed., vol. 30, no. 4, pp. 752-757, 2015.

[23] L. Weng, L. Huang, A. Taheri, and X. Li, "Rockburst characteristics and numerical simulation based on a strain energy density index: a case study of a roadway in Linglong gold mine, China," Tunnelling and Underground Space Technology, vol. 69, pp. 223-232, 2017.

[24] X. Li, Rock Dynamic: Fundamentals and Applications, Science Press, Beijing, China, 2014. 


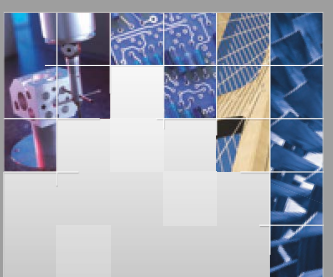

\section{Enfincering}
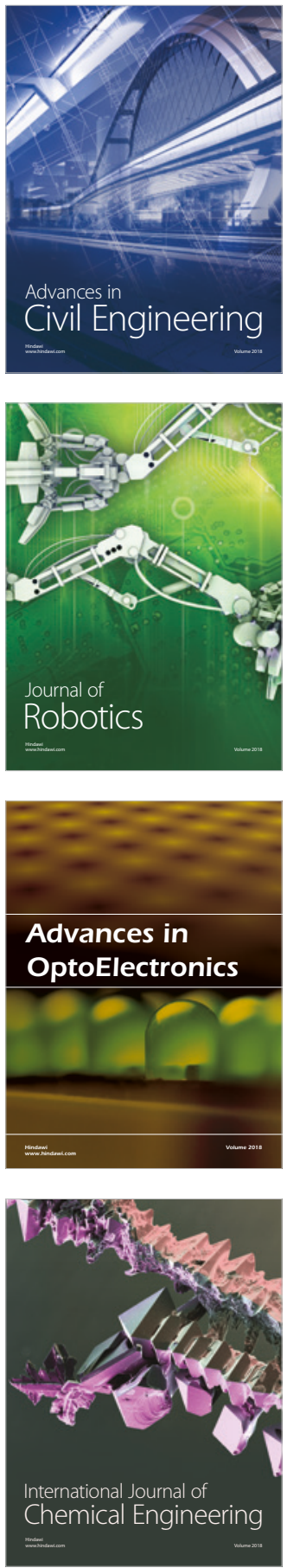

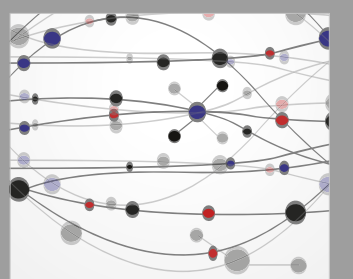

\section{Rotating \\ Machinery}

The Scientific World Journal

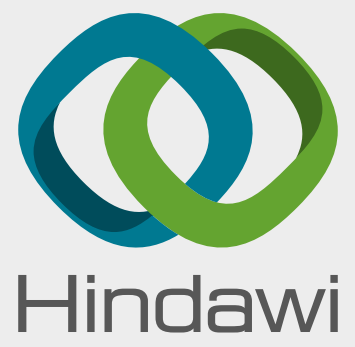

Submit your manuscripts at

www.hindawi.com
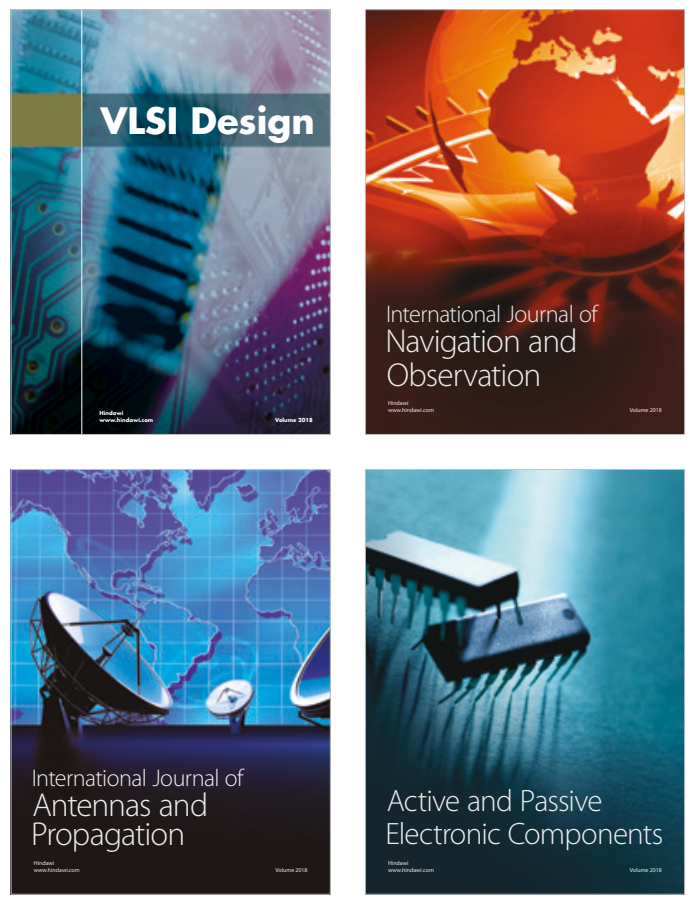
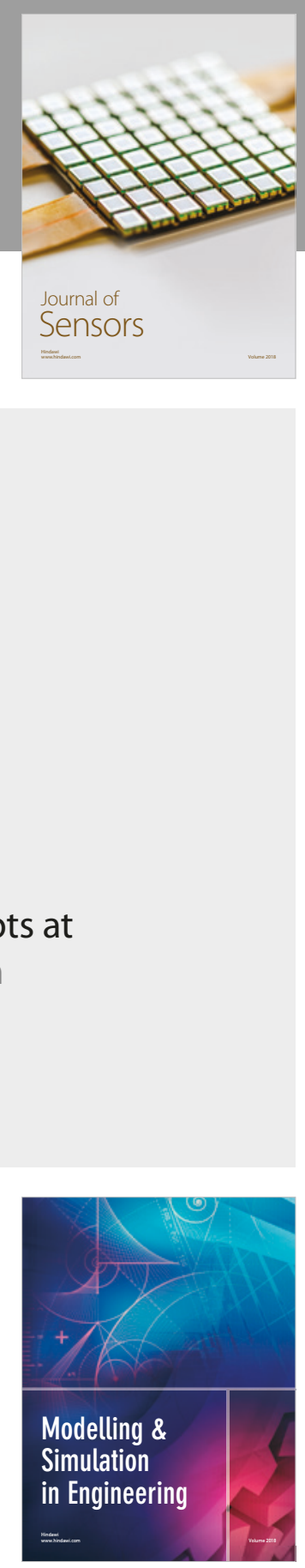

\section{Advances \\ Multimedia}
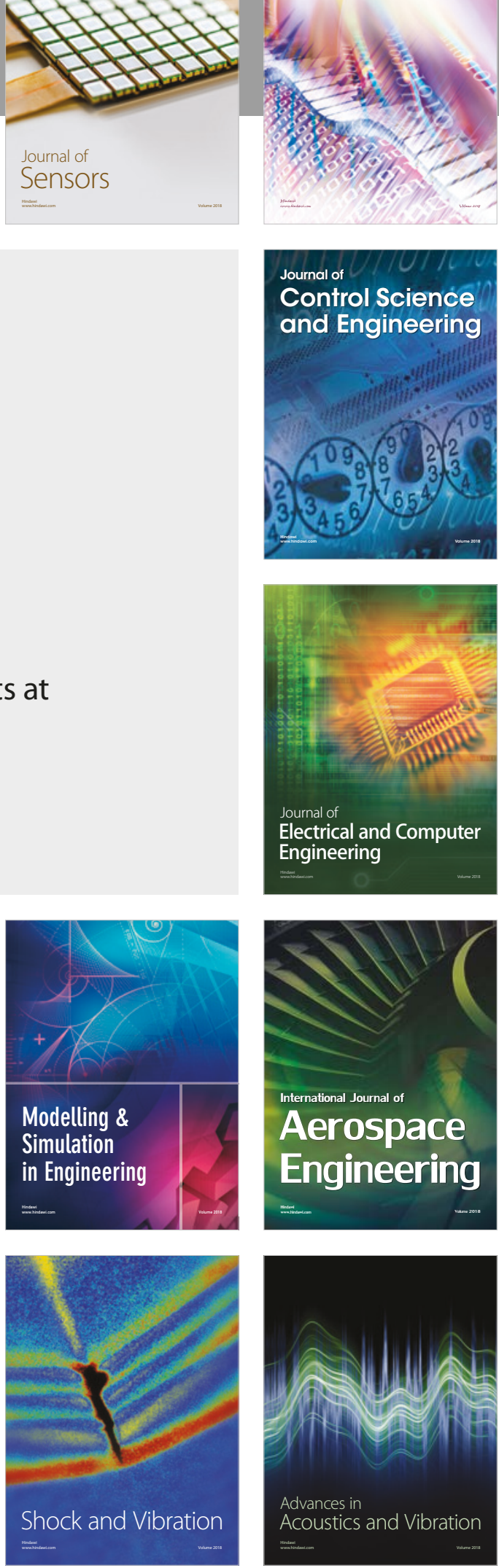